\title{
Maquiavelismo e sua relação com atividades contraproducentes nos estudantes de Ciências Contábeis
}

\section{Resumo}

Objetivo: Mensurar e classificar traços de personalidade maquiavelista com o propósito de associá-los a comportamento contraproducente em futuros profissionais da contabilidade.

Método: A amostra do estudo foi composta de 137 estudantes matriculados em quatro Instituições de Ensino Superior: duas públicas, uma localizada no Estado de Minas Gerais e a outra no Espírito Santo, além de duas particulares, ambas localizadas no Estado de Minas Gerais. Em relação aos procedimentos de coleta de dados, foram aplicados questionários a estudantes que já têm ou já tiveram alguma experiência profissional. Os dados foram utilizados em uma análise descritiva e quantitativa, com o propósito de verificar se a presença de traços de personalidade maquiavelistas pode estar relacionada à probabilidade de esses estudantes apresentarem comportamentos contraproducentes no trabalho.

Resultados: O perfil maquiavelista pode estar associado a cálculo estratégico, liderança, desejo de status, manipulação amoral e desonestidade; já o perfil de uma pessoa contraproducente está relacionado com a infração a normas e princípios da organização na qual o infrator está inserido, em decorrência, por exemplo, de furtos, fraudes contábeis ou mesmo baixa produtividade. Os resultados apontam para a preponderância de um perfil maquiavelista moderado entre os futuros profissionais de contabilidade, porém, não há evidências empíricas nesta amostra que possam levar à conclusão de que o maquiavelismo esteja relacionado ao comportamento contraproducente. A maioria dos entrevistados se autodeclaram com perfil baixo de contraproducência organizacional e interpessoal e há uma forte associação entre essas duas variáveis. Os resultados ainda permitem inferir que o traço de maquiavelismo, em média, é mais evidente nos homens do que entre as mulheres.

Contribuição: Entender que o perfil maquiavelista moderado não apresenta, necessariamente, comportamento contraproducente e contribui com a área de recursos humanos em seus processos seletivos e em avaliações periódicas.

Palavras-chaves: Maquiavelismo, Comportamento Contraproducente, Estudantes de Ciências Contábeis

\section{Ronilson Soares Aves}

https://orcid.org/0000-0002-8710-4958 Mestrando em Controladoria pela Universidade Federal de Minas Gerais (UFMG) e Professor na Fundação Educacional de Oliveira (FEOL) e Gestor na Cal Floresta Indústria e Comércio Ltda. Contato: Rodovia MG $050 \mathrm{~km}$ 214, s/ñ . (Caixa Postal 15). Zona Rural. Córrego Fundo (MG). CEP: 35.568-000. E-mail: soaresronilson@hotmail.com

\section{Lorenza Puppin Pinto Amaral Costa}

https://orcid.org/0000-0319-9981-6220 Especialista em contabilidade gerencial e planejamento tributário pela FUCAPE. Contato: Av. Pres. Antônio Carlos, 6627. Pampulha. Belo Horizonte (MG). CEP: 31.270-901.

E-mail: lorenzapuppin@hotmail.com

Eduardo Mendes Nascimento https://orcid.org/0000-0002-2188-9748 Doutor pela Universidade de São Paulo (USP) e Professor na Universidade Federal de Minas Gerais (UFMG). Contato: Av. Pres. Antônio Carlos, 6627. FACE - Sala 2039. Pampulha. Belo Horizonte (MG). CEP: 31.270-901. E-mail: e.mn@uol.com.br

Jacqueline Veneroso Alves da Cunha https://orcid.org/0000-0003-2522-3035 Doutora pela Universidade de São Paulo (USP) e Professora na Universidade Federal de Minas Gerais (UFMG). Contato: Av. Pres. Antônio Carlos, 6627. FACE - Sala 2039. Pampulha. Belo Horizonte (MG). CEP: 31.270-901. E-mail: jvac@face.ufmg.br 


\section{Introdução}

O comportamento profissional inspira pesquisa nas diversas áreas do conhecimento e, também, em Ciências Contábeis (Lopes, Cardoso, Reina \& Reina, 2016; Milan, 2014; Ferreira, 2013; Wakefield, 2008). Identificar o perfil comportamental de futuros profissionais da contabilidade contribui para entender o motivo pelo qual algumas decisões são tomadas ou, então, se o perfil influenciaria o fato de o indivíduo estar mais disposto a correr riscos para obter ganhos ou evitar perdas (Weller \& Thulin, 2012). Assim, antecipar a análise de traços de personalidade permitiria uma melhor adequação do profissional ao cenário organizacional.

Fundamentalmente, é necessário destacar que as avaliações de traços de personalidade são capazes de assinalar as características psicológicas mais marcantes de uma determinada pessoa, assim como categorizar o seu comportamento em diferentes ocasiões. Por isso, há uma grande variedade de testes de personalidade, sendo um deles aquele que permite identificar o grau de maquiavelismo um indivíduo (Noronha, 2002; Dalbosco \& da Silva Consul, 2011; Godoy \& Noronha, 2005; Rocha, Pinto \& da Silva, 2015).

Antes de tudo, porém, enfatiza-se que o maquiavelismo não é considerado um distúrbio de personalidade (Furnham, Richards, Rangel \& Jones, 2014). Segundo esses autores, o maquiavelismo é o único da tríade (maquievalismo/narcisismo/psicopatia) que não é visto assim, portanto, apenas como um traço de personalidade.

Maquiavelismo tem sido definido ao longo do tempo ora como um traço ou disposição da personalidade [...] ora como estratégia de conduta social [...], que envolve a manipulação de outros para obter ganhos pessoais. De um modo geral, [...] os indivíduos maquiavélicos tendem a ter uma relativa ausência de afeto nas relações interpessoais, não apresentam preocupação com a moral convencional, embora não sejam necessariamente imorais e demonstram baixo comprometimento ideológico. Além disso, eles consideram que os indivíduos altamente maquiavélicos superam aqueles menos maquiavélicos quando interagem em situações face a face, quando há espaço para a improvisação e em situações que envolvem detalhes afetivos que são considerados como irrelevantes para a vitória [...]. [...] maquiavélicos devem ser vistos não como antiéticos, mas como indivíduos capazes de sacrificar a ética, segundo seus interesses (Lustosa, Roazzi \& Camino, 2004).

A má fama a respeito desse traço de personalidade encontra fundamento nos pensamentos políticos de Niccoloò Machiavelli, que, em sua obra, teria abordado um viés político controlador, em que ideias como a "mentira, percepção, manipulação e convencimento dos eleitores, com o objetivo de fornecer ao líder o poder político e social" (Judge, Piccolo \& Kosalka, 2009, pg.866) fizeram e fazem sucesso até os dias atuais.

Ocorre que os detratores da obra de Maquiavel, ao que tudo indica, ignoram o contexto histórico e político de suas análises, rotulando-o, superficialmente, como o precursor do pensamento segundo o qual "os fins justificam os meios". Ainda que não seja propriamente o objeto desse trabalho, convém, resumidamente, destacar a impropriedade histórica da terminologia maquiavelismo para designar comportamentos egoísticos e manipuladores, sempre com um viés negativo: Maquiavel nasceu em Florença, no dia 3 de maio de 1469, e sua obra está permeada pelo cenário político da época, marcada pela divisão da Itália em diversos principados despóticos. De forma muito singela, é possível afirmar que uma das maiores preocupações do florentino era justamente a unificação italiana. De acordo com Gomes (1990, pag. 101),

[...] o Livro O Principe fala de um momento de exceção onde o Estado tem que ser constitu[ido e tem como pano de fundo a Itália dividida e explorada. É necessária, nesse momento, a instauração de um poder unidicador. [...] Se o príncipe governa com poderes extraordinários é para instaurar a ordem e tão logo isto seja feito, seguramente o deial de Maquiavel é que se constitua, então uma república.

Ainda, “[...] o exercício dos poderes de exceção do príncipe deve ser passageiro. Tão logo a ordem for estabelecida ou restbelecida, o poder deve passar para as mãos da maioria a quem efetivamente compete governar [...]" (Gomes, 1990, pág. 102-103). 
Nesse cenário, explica Alves (2008, pág. 8) que

A crítica feita a Maquiavel restringe-se ao fato de ele ter supostamente afirmado que o governante pode fazer tudo o que for necessário para atingir o poder e conservá-lo. Dessa forma, o poder seria um fim em si mesmo, que não dependia de nada além do desejo de conquistá-lo e da habilidade em mantê-lo para legitimar-se. De fato, qual problemática de fundo que ocupa Maquiavel em suas especulações políticas? Ora, a questão da qual se ocupa Maquiavel é a de saber se o governante pode agir sempre de acordo com os princípios éticos cristãos aceitos em seu tempo e esperar atingir seus objetivos, ou se deve aprender a seguir outros caminhos, quando confrontado com situações difíceis. Ele não aconselha aos governantes a desrespeitar as regras aceitas pelo mero prazer de fazê-lo. Ao contrário, explicita que este deve se comportar de acordo com elas sempre que possível. Quanto a isso, afirma que é louvável a um príncipe manter a fé e viver com integridade sempre que possível' [...]. O que ele deseja saber é se isso de fato é possível. Em outras palavras, se a ética é suficiente para mostrar como agir na política em todas as situações. Maquiavel parte de uma evidência, ou seja, do que são os conflitos nas cidades para elaborar suas idéias. Convêm lembrar que para o autor a natureza humana é altamente negativa. A maldade dos homens deve ser compreendida como uma característica destes e que se torna fundamental quando se refere à esfera política.

Apesar das críticas acima expostas, a terminologia "maquiavelismos" é utilizada neste trabalho, pois é amplamente aceita no contexto acadêmico, tendo sido, ao longo dos anos, imbuída de significado por vários ramos do conhecimento. Nesse sentido, o traço de personalidade maquiavelista foi definido pelos autores Christie e Geis em 1970. Eles buscaram definir características, como a destreza, a manipulação, assim como a busca infindável por meios necessários para atingir um objetivo de natureza política. De acordo com Judge et al. (2009), as pessoas que têm esse traço de personalidade são bastante estratégicas e calculistas no seu modo de pensar, além de manipularem os outros de acordo com seus interesses. Além das já citadas, são características do Maquiavelismo: "reputação, cinismo, cálculo estratégico, tática, orientação para o futuro, baixos padrões de ética e moral, estratégia, ausência de princípios, amoralidade e flexibilidade" (D’Souza, 2016, p. 23). Os indivíduos com traços de maquiavelismo não sentem culpa diante de comportamentos antiéticos (Murphy, 2012).

Torna-se necessário analisar as definições dadas ao ato de desonestidade, sendo que uma delas pode ser determinada como comportamento contraproducente no ambiente de trabalho (Ferreira, 2013), objeto de estudo em questão. De acordo com Robinson e Bennet (1995), comportamento contraproducente é aquele que infringe as normas e os princípios da organização, ameaçando o bem-estar do meio. Esses comportamentos interferem no desenvolvimento saudável da organização (Marcus \& Schuler, 2004; Vardi \& Weitz, 2004). Para que um comportamento seja avaliado como contraproducente, é necessário que ele constitua um ato indesejável e que não combine com os interesses da organização (Marcus \& Schuler, 2004). Ademais, é necessário que ele tenha caráter intencional, pois atos como esses podem influenciar, significativamente, a situação financeira da organização (Rotundo \& Sackett, 2002).

Por isso, este estudo se propõe a analisar traços de personalidade maquiavélicos, nos níveis baixo, moderado e alto (Lopes et al., 2016), e como estes podem estar relacionados a atitudes contraproducentes nas rotinas de futuros profissionais da contabilidade. Dessa maneira, o problema de pesquisa foi: Qual a relação entre os traços de personalidade maquiavélicos e os traços de contraproducência nos futuros profissionais de contabilidade?

Foram aplicados 137 questionários a futuros profissionais da contabilidade, que já exercem ou já exerceram uma atividade profissional. Os instrumentos de medição de personalidade que foram utilizados são: Short Dark Triad (SD3), que além de medir comportamentos como o narcisismo e a psicopatia, também mede o perfil do maquiavelista (foco desse estudo), sendo 9 perguntas para cada uma dessas analises; e o Workplace Deviance Scale (WDS), com 12 itens que se propõem a avaliar tendências de manifestação de Comportamento Contraproducente Organizacional (CCT-O) e 7 que buscam avaliar Comportamento Contraproducente Interpessoal (CCT-I) no ambiente de trabalho, de modo explícito. 
Tais questionamentos se justificam, uma vez que a análise do perfil do empregado de contabilidade pode ajudar a organização a criar estratégias de gerenciamento de pessoal, evitando, assim, problemas de relacionamento interno e até mesmo prejuízos financeiros para o mundo corportativo (Zettler, Friedrich \& Hilbig, 2011). Parte-se do pressuposto de que a identificação das origens de tais comportamentos pode contribuir para a prevenção e o desenvolvimento da organização do trabalho e para o bem-estar intergrupo (D’Godoy \& Noronha, 2005). Além disso, estudos que envolvem a Dark Triad consistem em uma boa oportunidade de pesquisa, especialmente pela interdisciplinariedade e relevância dessa temática (D’Souza \& Jones, 2017).

Cabe ressaltar que o comportamento maquiavelista nem sempre está associado a comportamentos ruins para a empresa, pelo contrário, existem autores (Judge et al., 2009; Zettler, et al., 2011; Jones \& Paulhus, 2010) que indicam que profissionais com essas características seriam de grande utilidade para a organização. D’Souza (2016, p.23) considerou que realmente existem características negativas associadas ao Maquiavelismo; em contrapartida, algumas repercutem positivamente no ambiente de trabalho, principalmente para cargos de liderança, tais como orientação para o futuro, capacidade de formular estratégia e flexibilidade.

Também, o estudo pode contribuir com discussões que associam o perfil maquiavélico a pessoas que atuam desonestamente em seus ambientes de trabalho, como os comportamentos já associados ao maquiavelismo e discutidos anteriormente. O que se pretende com este estudo é identificar em que grau indivíduos com médios/altos traços de maquiavelismo apresentam comportamentos contraproducentes nas organizações em que atuam.

\section{Referencial Teórico}

Neste capítulo discutem-se as bases que serviram de direcionadores para o trabalho, tais como: definição do comportamento contraproducente no trabalho e do perfil maquiavélico, além de instrumentos para a medição dessas variáveis. Ao final são apresentadas pesquisas que trazem evidência sobre como essas duas variáveis se relacionam e a construção de hipóteses elaboradas de modo a testar aquela relação e também para analisar a associação tanto do comportamento contraproducente quanto do perfil maquiavelista com o perfil dos respondentes.

\subsection{Comportamento contraproducente no trabalho}

De acordo com Robinson e Bennet (1995), comportamento contraproducente é aquele que infringe as normas e os princípios da organização, seja em cargos hierarquicamente altos ou baixos (Vardi \& Weitz, 2004), ameaçando o bem-estar do meio. São atos com intenção de prejudicar o bom funcionamento da organização e das pessoas que nela trabalham. Esses comportamentos interferem no desenvolvimento próspero da organização (Marcus \& Schuler, 2004, Vardi \& Weitz, 2004).

Seriam os envolvimentos dos empregados com furtos e/ou a falta de produtividade, mas, em alguns casos, esse comportamento não se mostra tão evidente, pois o funcionário usa de meios que, até então, seriam considerados "legais" para justificar sua contraproducência, como, por exemplo, quando falta ao trabalho em muitas ocasiões se justifica por meio de atestados médicos. Faltar em razão de uma doença não é considerado contraproducente; o que seria considerado como tal é o fato de apresentar vários atestados quando não se está vivenciando um problema real com uma doença (Cullen \& Sackett, 2003). Assim, esse comportamento precisa ter caráter intencional e, não, acidental (Ferreira, 2013).

A contraproducência existente no meio organizacional pode-se dar por uma ou mais situações específicas. Essas situações podem estar relacionadas a 
Pressões financeiras ou sociais, tratamentos injustos, condições precárias de trabalho ou outro episódio que possam causar um senso de disparidade e/ou ofensa, provocando no indivíduo um desejo de lidar com a questão ou expressar sua insatisfação por meio do comportamento contraproducente (Ferreira, 2016, p. 8).

Esses seriam os fatores motivadores, mas, além desses, também é necessário levar em consideração os fatores individuais de personalidade, como a responsabilidade da pessoa, sua maneira de se adaptar e de se relacionar, como também sua estabilidade emocional (Dalal, 2005).

Este trabalho utilizará escalas que avaliam o comportamento contraproducente (CCT) na organização. A escala Workplace Deviance Scale (WDS), desenvolvida por Rebecca J. Bennett e Sandra L. Robinson, publicada em 2000, avalia tais comportamentos por meio de conteúdos diretos, envolvendo, principalmente, roubo, agressões físicas, sabotagem, absenteísmo e outros comportamentos considerados desonestos.

Essa escala de avaliação divide o comportamento contraproducente em duas vertentes: organizacional e interpessoal. A organizacional trata das relações existentes entre os membros da organização, e por isso se avalia um relato de atitudes próprias, por exemplo: se a pessoa procrastina o trabalho para ganhar hora extra, se trabalha intencionalmente mais devagar do que poderia, entre outras. A Interpressoal está voltada para comportamentos que visam prejudicar as relações existentes dentro da organização, em contextos nos quais outras pessoas estariam envolvidas, como: fazer piada de alguém, insultar alguém, agir de maneira grosseira dentro do ambiente organizacional, etc. (Bennett \& Robinson, 2000).

Os estudos voltados para a compreensão de comportamentos revelados no ambiente de trabalho mostram que os CCTs interferem no desenvolvimento saudável da organização (Fine, Horowitz, Weigler, Basis, 2010; Marcus \& Schuler, 2004; Vardi \& Weitz, 2004).

\subsection{Abordagem do perfil maquiavélico}

A conduta das pessoas pode ser resumida, prevista e explicada pelos traços de personalidade, definidos como "[...] características internas, relativamente estáveis, consistentes e permanentes, que são deduzidas a partir de um padrão de comportamento, atitudes, sentimentos e hábitos de indivíduo" (VandenBos, 2010, p. 701).

Em 2002, Paulhus e Williams desenvolveram um instrumento capaz de estudar o comportamento de indivíduos que apresentam traços, não patológicos, de narcisismo, maquiavelismo e psicopatia, por eles denominados Dark Triad. Os três perfis possuem algumas similaridades (insensibilidade e manipulação), apesar das suas diferenças (D'Souza, 2016). O objetivo dessa ferramenta é analisar e compreender “tendências de disposições, por meio de um questionário do tipo autorrelato" (D’Souza, 2016, p. 21) sem a intenção de diagnosticar transtornos de personalidade ou problemas psicológicos (Furnham, Richard \& Paulhus, 2014; Almeida, Laranjeira \& Dractu, 1996).

O maquiavelismo, foco dessa pesquisa, é um dos perfis analisados pelo Dark Triad, por meio de um questionário Short Dark Triad SD3. O termo "maquiavelismo" é proveniente da obra "O Príncipe", de 1513. Tema de pesquisas na área gerencial, esse perfil psicológico exerce grande influência nas decisões profissionais e consequentemente sobre o mundo dos negócios (Cyrac \& Dharmaraj, 1994). ).

Existem pesquisas que elucidam comportamentos bons e ruins associados a indivíduos com traços de maquiavelismo. Assim, quando se investigam os traços de Maquiavelismo, percebe-se uma personalidade caracterizada por uma "[...] atitude calculista em relação a relacionamentos humanos e uma crença de que os fins justificam os meios, embora desumana" (VandenBos, 2010, p. 574).

O maquiavelista busca incessantemente pelo êxito (vitória), assim, seu interesse pessoal impera sobre todas as coisas, e a decisão associada à ética é facilmente descartada (Milan, 2014). Segundo Zettler \& Hilbig (2010), funcionários com esse perfil se concentram em fazer sua carreira satisfazendo apenas às suas necessidades pessoais, esforçando-se para tirar o máximo proveito da situação, daí porque o comprometimento com a equipe acaba ficando em segundo plano. Dessa forma, esse traço de personalidade pode levar ao ápice ou ao declínio profissional (Mynatt, Omundson, Schroeder \& Stevens, 1997). 


\subsection{Evidências Empíricas sobre Maquiavelismo e Comportamento Contraproducente dos profissionais contábeis}

Uma pesquisa com controladores/contadores gerenciais realizada por Hartmann e Maas (2010) que avaliava a suscetibilidade de envolvimento em criação de folgas orçamentárias, constatou que um perfil maquiavélico alto tem mais chances de ceder a pressões administrativas e a criar folga orçamentária quando precisa tomar decisões. A expectativa do profissional com essas características é de que ele consiga um desempenho sempre superior ao dos outros, mesmo quando isso não é a realidade factual (Jain \& Bearden, 2011). ).

Em 2008, os autores Shafer e Simmons pesquisaram a relação existente entre responsabilidade social, o maquiavelismo e a evasão fiscal nos profissionais fiscais de Hong Kong e encontraram indícios de que o maquiavelismo afeta os pontos de vista expressos pelos profissionais fiscais quanto à importância ética corporativa e a responsabilidade social, além de afetar no julgamento profissional em direção a uma minimização fiscal agressiva.

Outro estudo que relacionou o perfil maquiavélico do contador inferiu que aqueles que possuem perfil considerado alto no maquiavelismo são mais suscetíveis a cometer fraude nos relatórios se tiverem oportunidade, justamente pela ausência de culpa diante do comportamento antiético (Murphy, 2012). A pesquisa de Wakefiel (2008) considera que o grau de maquiavelismo do contador é menor do que de outros grupos profissionais. Contudo, existem outros estudos que rebatem essa conclusão, encontrando um escore maior do grau do maquiavelismo no contador em relação a outras profissões, principalmente em relação a profissões ligadas a área social (Roodpooshiti, Nikoomaram \&Mahfoozi, 2012).

Pessoas com o perfil maquiavélico podem ser consideradas estrategistas e calculistas no modo de pensar, além de terem destreza para atuarem em negócios complexos (Judge et al., 2009, Jones \& Paulhus, 2011). Esse perfil nos profissionais contábeis seria de grande utilidade no meio empresarial, uma vez que ajudaria na tomada de decisão em curto, médio e longo prazo. Ainda, de acordo com as análises da pesquisa de Zettler e Solga (2013), pessoas com alto grau de maquiavelismo têm melhor comportamento de cidadania organizacional que os que apresentaram um grau menor, mesmo tendo problemas do ponto de vista ético (Kish-Gephart, Harrison \& Treviño, 2010, Malinowski, 2009).

Já com relação ao comportamento organizacional, pessoas com alto perfil maquiavélico apesentam maior comprometimento na carreira, menor comprometimento organizacional (Zettler, Friedrich \& Hilbig, 2011), mais influência comportamental (Barbuto \& Moss, 2006) e mais contraproducência comportamental (O’Boyle, Forsyth, Banks \& McDaniel, 2012), reforçando ainda mais a ideia de que esse tipo de personalidade se preocupa mais consigo mesmo, deixando um pouco de lado o interesse e o bem-estar coletivos.

O trabalho de Dahling, Whitaker e Levy (2009) também considera que perfis maquiavélicos altos são propensos a comportamentos contraproducentes e, consequentemente, a ações que prejudicam o bem-estar da organização (Fox \& Spector, 1999). A pesquisa de Harrell e Hartnagel (1976) mostrou que perfis maquiavélicos altos de empregados estavam dispostos a roubar tanto de um supervisor que confiava neles quanto de um que desconfiava, enquanto os de perfil maquiavélico baixo estavam menos dispostos a roubar do supervisor confiável, por um senso de reciprocidade. Tal ação está ligada ao comportamento contraproducente organizacional, quando tratada apropriação de bens no local de trabalho sem permissão.

Com base no que foi exposto, construíram-se as seguintes hipóteses de pesquisa:

- $\mathbf{H}_{1}$ : Há uma relação positiva e significativa entre o traço de maquiavelismo e comportamento contraproducentes. 
Em relação às características dos indivíduos, alguns estudos sustentam que o maquiavelismos está frequentemente associado ao sexo dos indivíduos (homens apresentam traços maiores de maquiavelismo, o que seria explicado pela teoria dos Papéis Sexuais) (Webster \& Harmos, 2002, Bolino \& Tunley, 2003, Sweeney, Arnold \& Pierce, 2009, Grohmann \& Battistella, 2012, D’Souza \& Lima, 2018, D'Souza, Lima, Jones, Daniel, \& Carré, 2019). Esses estudos indicam que essa associação entre perfil maquiavelista e sexo está ligado ao contexto em que os indivíduos vivem e se relacionam. Isso se observa em ambientes machistas em que os homens são demandados a terem posturas associadas às características daquele perfil. Por um anglo semelhante, estudos anteriores mostraram (War \& Beck, 1990, Avelino \& Lima, 2017) que o comportamento contraproducente pode ser observado mais em homens do que em mulheres, porque as mulheres são socializadas para obedecer às regras, enquanto a socialização para os homens é menos restritiva nesse aspecto.

Assim, as hipóteses 2 e 3 são construídas conforme segue:

- $\mathbf{H}_{2}$ : Há uma relação significativa entre o sexo dos respondentes e o perfil maquiavélico.

- $\quad \mathbf{H}_{3}$ : Há uma relação significativa entre o sexo dos respondentes e o comportamento contraproducente

A respeito do estado civil dos respondentes, algumas evidências sugerem que pessoas casadas tendem a apresentar um perfil maquiavélico mais marcado, pois elas buscam maior estabilidade e, portanto, estão mais dispostas a buscar meios que lhes proporcionem maior segurança em seu ambiente social (Lima, Garcia \& Pereira, 2012). Mas em relação aos solteiros, há relatos de que eles apresentam maior nível de comportamento contraproducente, face a sua disposição em assumir comportamentos mais arriscados do que seus pares (Lima, Garcia \& Pereira, 2012).

- $\quad \mathbf{H}_{4}$ : Há uma relação significativa entre o perfil maquiavélico e o fato de o indivíduo ser casado.

- $\quad \mathbf{H}_{5}$ : Há uma relação significativa entre o comportamento contraproducente e o fato de o indivíduo ser solteiro.

Foi realizada também a construção de duas hipóteses referentes à relação entre os contextos da IES dos estudantes. Acredita-se que os estudantes de IES públicas sofrem maior cobrança por desempenho, isso desde o ingresso, considerando que o vestibular busca selecioná-los apenas por avaliações; e também durante o curso, pensando que as oportunidades institucionais que lhes são oferecidas são condicionadas ao seu desempenho, quer seja nas disciplinas, quer seja pelo próprio processo seletivo a que se submetem (Formiga, 2004, Santos, 2012, Bublitz, Guido, Lopes \& Freitas, 2016). Também, socialmente, é exigido dos estudantes das IES públicas a obtenção de melhores resultados (desempenho acadêmico e profissional), pois, por terem tido a oportunidade de estudar em um ambiente custeado pela gestão pública, recai sobre eles a obrigação de se tornarem indivíduos com maior destaque e produtividade e, ao não se desincumbirem satisfatoriamente desse ônus, podem ter seu comportamento associado à desvalorização dessa chance. Por tudo isso é que se acredita que os estudantes de IES públicas são sujeitos com traços maquiavelista mais acentuados e mesmo com comportamentos contraproducentes, com o objetivo de atingir esses anseios.

- $\quad \mathbf{H}_{6}$ : Há uma relação significativa e positiva entre o perfil maquiavélico dos estudantes de IES públicas quando comparados com os de IES privadas.

- $\quad \mathbf{H}_{7}$ : Há uma relação significativa e positiva entre o comportamento contraproducente dos estudantes de IES públicas quando comparados com os de IES privadas. 
Em relação à idade, os resultados são controversos. Ora se observa que a idade é capaz de influenciar tanto o desenvolvimento de personalidade maquiavélica quanto o comportamento contraproducente, porém, em outros momentos, os resultados indicam não haver relação (Cullen \& Sackett, 2003, Sweeney, Arnold \& Pierce, 2009, D’Souza, 2016); ora, o cenário organizacional dificulta o reconhecimento e a representação de eventos cotidianos, uma vez que essas circunstâncias ambientais são cada vez mais complexas. Por exemplo, fatores como globalização, tecnologia, legislação, diversidade da força de trabalho, descentralização, aumento de conhecimento e necessidade de mudanças rápidas e adaptabilidade contribuem para o aumento das complexidades e ambiguidades associadas ao ambiente de trabalho de hoje, o que repercute em desafios aos indivíduos (Thiel, Bagdasarov, Harkrider, Johnson \& Mumford, 2012). Tudo isso se junta ao desejo de as pessoas buscarem estabilizar suas vidas, o que desafia seus padrões éticos e valores (Sweeney, Arnold \& Pierce, 2009). Por outro lado, conjectura-se que à medida que uma pessoa envelhece, seus valores se tornam mais rigorosos e, portanto, suas crenças e comportamentos tornam-se cada vez mais importantes, o que motiva o indivíduo a perseguir modelos comportamentais mais éticos (Cullen \& Sackett, 2003). ). A partir desse argumento, tem-se as hipotéses a seguir.

- $\quad \mathbf{H}_{\mathbf{8}}$ : Há uma relação significativa e positiva entre o perfil maquiavélico e a idade do respondente.

- $\quad \mathbf{H}_{9}$ : Há uma relação significativa e positiva entre o comportamento contraproducente a idade do respondente.

\section{Metodologia}

A pesquisa em questão é de natureza descritiva, pois tem o objetivo de analisar o evento como acontece na prática, utilizando-se, portanto, de survey. Quanto à abordagem, é considerada quantitativa. Em relação à estratégia, o presente estudo pode ser apreciado como um levantamento, pois faz uso de fontes primárias, a fim de atender ao seu objetivo de analisar a associação entre traços de personalidade maquiavelistas e comportamentos contraproducentes no trabalho em relação aos futuros profissionais da contabilidade (Marconi \& Lakatos, 2002).

\subsection{Questionário}

O instrumento utilizado se consistiu em quatro partes: (i) termo de consentimento livre e esclarecido (TCLE); (ii) informações socioeconômicas sobre o participante, incluindo informações sobre gênero, idade, estado civil, raça, exercício de alguma atividade profissional (estágio ou CLT), se possui vínculo profissional atual, renda, tempo de experiência profissional e satisfação com o local de trabalho; e (iii) 9 questões que avaliam o grau de maquiavelismo extraído do Short Dark Triad - SD3 (Paulhus \& Williams, 2002). ). A versão em portugues do SD3 foi a desenvolvida por D’Souza (2016). Essa autora realizou a tradução por meio de uma metodologia conhecida como tradução reversa (back translation) com um total de sete tradutores envolvidos. Operacionalmente, três profissionais traduziram para o português, depois disso, essas três traduções foram enviadas para mais três profissionais, que as traduziram novamente para o inglês; e, por fim, as seis traduções foram validadas por outro tradutor com habilitação na área de psicologia (D’Souza, 2016). Para este estudo, utilizamos apenas as nove primeiras questões do SD3, que identificam comportamentos maquiavélicos. Os itens foram avaliados em uma escala de cinco pontos do tipo Likert, em que 1 faz referência a "Discordo totalmente", 2 "Discordo", 3 "Não concordo nem discordo", 4 "Concordo" e 5 "Concordo totalmente"; e (iv) 19 questões com objetivo de identificar comportamentos contraproducentes no ambiente profissional por meio do Workplace Deviance Scale (WDS) (Bennett \& Robinson, 2000) na versão para o contexto brasileiro desenvolvido por Nascimento, Araújo, Andrade e Mendonça (2015). Depois de obtida autorização das autoras originais, pesquisadores da Universidade 
Federal de Minas Gerais da área de Psicologia fizeram a tradução do referido questionário, utilizando-se também da ferramenta de tradução reversa (Nascimento et al., 2015). Os itens foram avaliados em uma escala de cinco pontos do tipo Likert, em que 1 faz referência a "Nunca", 2 "Muito raramente", 3 "Raramente", 4 "Ocasionalmente", 5 "Frequentemente", 6 "Muito frequentemente" e 7 "Sempre". Ambas as escalas seguiram as utilizadas pelos pesquisadores nacionais na tradução dos instrumentos.

No trabalho de D'Souza (2016), o critério de classificação adotado foi: (i) - inicialmente foi mensurada a média de cada indivíduo e em seguida calculada a mediana do grupo; (ii) para análise foram considerados: Baixos traços - resultados que estiveram abaixo da mediana; Moderados traços - resultados na mediana; e Altos traços - resultados acima da mediana. Para permitir melhor relação entre as variáveis "maquiavelismo" e "contraproducência", este estudo adotou o tercil para segregação da amostra em níveis baixo, moderado e alto de maquiavelismo e contraproducência. O cálculo dos tercis foi obtido por meio da divisão da amplitude amostral por três para cada uma das variáveis que compõem a amostra. O nível baixo refere-se à menor amplitude e assim sucessivamente para os demais níveis considerados (D’Souza, 2016).

Visando garantir a validade do instrumento ao contexto estudado, foi realizado um pré-teste, buscando-se maior acurácia, de modo que os dados levantados pudessem ser a representação mais precisa possível do contexto estudado. Assim, foi realizado um pré-teste com 3 alunos de um curso de mestrado em Contabilidade mineiro para identificar possíveis problemas com as questões, tendo-se verificado que o instrumento estava adequado ao seu contexto. Portanto, o instrumento era válido para levantar as informações que subsidiaram os indícios discutidos nesta pesquisa.

Para analisar a confiabilidade do questionário, foi realizado o teste de alfa de Cronbach. Com relação às evidências psicométricas da escala fornecidas pelas autoras do instrumento, Nascimento et. al (2015), apresentaram um alfa de 0,81 para a escala de desvio organizacional (CCT-O) e 0,77 para desvio interpessoal (Ferreira, 2013); com relação ao alfa do Maquiavelismo, um estudo desenvolvido por D'Souza (2016) encontrou um alfa de Cronbach de 0,75. Assim, o presente estudo resulta em confiabilidade próxima das apresentadas quando da criação e da tradução dos questionários, sendo os resultados dessa pesquisa: Alfa de Cronbach Geral de 0,72, MQ de 0,66, CCT-O de 0,81 e CCT-I de 0,77.

\subsection{Variáveis Analisadas}

O mapeamento da parte empírica deste estudo foi baseado nas relações correlacionais das variáveis de forma que fosse possível descrever as relações que ocorrem naturalmente entreelas, sendo apresentado na Figura 1.

\begin{tabular}{|c|c|c|}
\hline X Conceitual & \multirow{5}{*}{$\leftarrow \rightarrow$} & Y Conceitual \\
\hline Maquiavelismo & & $\begin{array}{l}\text { Comportamento } \\
\text { Contraproducente }\end{array}$ \\
\hline$\downarrow$ & & $\downarrow$ \\
\hline X Operacional & & Y Operacional \\
\hline $\begin{array}{l}\text { Escore alcançado nas } \\
09 \text { questões do Short } \\
\text { Dark Triad (SD3) } \\
\text { que se referem ao } \\
\text { Maquiavelismo }\end{array}$ & & $\begin{array}{l}\text { Escore alcançado no } \\
\text { Workplace Deviance Scale } \\
\text { (WDS) subdivido nas } \\
\text { suas duas categorias: } \\
\text { comportamento } \\
\text { contraproducente - } \\
\text { Interpessoal (CCP-I) } \\
\text { e comportamento } \\
\text { contraproducente - } \\
\text { organizacional (CCP-O) }\end{array}$ \\
\hline
\end{tabular}

Figura 1. Desenho da Pesquisa 


\subsection{Amostra}

Foram distribuídos 200 questionários a quatro instituições de Ensino Superior (IES): duas públicas, Universidade Federal de Minas Gerais (UFMG) (localizada em Belo Horizonte-MG) e Universidade Federal do Espírito Santo (UFES) (localizada em Vitória - ES), e duas IES particulares, localizadas em MG (UNIFOR-MG) (Universidade de Formiga) e Faculdades Pitágoras (Unidade Divinópolis). As instituições de ensino e os respondentes foram selecionados com base nos critérios de acessibilidade, fato que requer mais cuidado para a realização de inferências, uma vez que a população da qual a amostra foi selecionada pode ser substancialmente diferente. Assim, os resultados não podem ser generalizados para a população, pois se restringem à amostra analisada.

Quanto aos procedimentos de coleta de dados, optou-se pela aplicação de um questionário aos estudantes que já atuaram ou que atuam em alguma organização. Os respondentes de instituição pública tiveram acesso ao questionário impresso, aplicado na presença dos pesquisadores com o consentimento dos docentes das disciplinas. Já os respondentes das instituições privadas tiveram acesso ao questionário impresso, contudo, a instituições não permitiram a presença dos pesquisadores no local, então apenas a coordenação estava presente. Os dados foram coletados durante os meses de maio e junho de 2017.

Obteve-se retorno de 149. Alguns não foram respondidos totalmente, o que impossibilitou a análise; outros não foram respondidos, o que ocasionou numa amostra final de 137 estudantes de Contabilidade dos cursos de graduação em Ciências Contábeis.

\subsection{Análise dos dados}

Antes da realização de testes estatísticos, é necessária a descrição dos dados que compõem a amostra do estudo por meio de uma análise descritiva. A descrição da amostra que compõe o presente estudo é feita por meio de gráficos e tabelas que objetivam evidenciar tendências e favorecer a análise subsequente dos dados.

O pressuposto inferencial de que os dados são provenientes de uma certa população e se distribuem segundo a distribuição Normal é a base para a aplicação de diversos testes estatísticos. A verificação da existência de normalidade dos dados é dada pela aplicação de um teste de normalidade. Entre os diversos testes constantes na literatura, tem-se o teste de Kolmogorov Smirnov, que faz a comparação da diferença máxima absoluta entre a função de distribuição acumulada da distribuição Normal e a distribuição empírica dos dados amostrados. O teste apresenta hipótese nula de normalidade dos dados contra a alternativa de ausência de normalidade (Siegel \& Castellan Jr., 2006).

No presente estudo, objetivou-se verificar a existência de diferenças significativas, em relação ao maquiavelismo e ao comportamento contraproducente, segregados em relação a variáveis sociais, tais como gênero, raça, renda, etc. A comparação dos valores médios de duas variáveis em termos de existência de diferença significativa pode ser feita por meio de um teste não paramétrico, de Mann-Whitiney. A principal diferença entre os testes te de Mann-Whitiney relaciona-se à distribuição dos dados amostrais. O teste $t$ apresenta como pressuposto a normalidade dos dados, diferentemente do teste não paramétrico, de Mann-Whitiney, também conhecido como teste U, que verifica a presença de diferença significativa entre os valores mediados dos dados amostrados e não requer o pressuposto de normalidade dos dados (Devore, 2006).

Para a consecução dos objetivos propostos, faz-se necessária a verificação da existência de relacionamento entre as variareis que fazem parte do presente estudo. A investigação da existência de relação entre as variáveis pode ser feita pelo coeficiente de correlação de Pearson ou coeficiente de correlação de Spearman. O primeiro coeficiente pressupõe a existência de um relacionamento linear entre as variáveis e requer, ainda, que elas sejam mensuradas em um intervalo de classe. 
A segunda abordagem estatística, o coeficiente de correlação de Spearman, é uma técnica não paramétrica - não necessita da garantia de existência de normalidade dos dados não exigindo, portanto, $a$ priori, nenhum tipo de suposição sobre a distribuição das variáveis analisadas. O coeficiente de Spearman apresenta, também, a vantagem de não captar, estritamente, o relacionamento linear entre as variáveis estudadas (Siegel \& Castellan Jr., 2006).

\section{Resultados}

A seguir são apresentadas as estatísticas descritivas da amostra que compõem o presente estudo. A Tabela 1 apresenta os resultados evidenciados na amostra do presente estudo em relação a partições amostrais que tratam de aspectos sociais tais como: gênero, raça, tipo de instituição de ensino (pública ou privada) e estado civil. O perfil médio dos respondentes foi de indivíduos do gênero feminino (53\%); aqueles que se descrevem como da raça branca são $56 \%$ dos entrevistados; solteiros são $86 \%$ e a maioria são estudantes de universidades públicas.

\section{Tabela 1}

\section{Distribuição dos Respondentes por gênero, raça, estado civil, ensino público ou particular dos participantes}

\begin{tabular}{|c|c|c|c|}
\hline \multicolumn{2}{|c|}{ Variável } & \multicolumn{2}{|c|}{ Frequência } \\
\hline & Distribuição & Absoluta & Relativa \\
\hline \multirow{3}{*}{ Sexo } & Feminino & 73 & $53 \%$ \\
\hline & Masculino & 64 & $47 \%$ \\
\hline & Total & 137 & $100 \%$ \\
\hline \multirow{6}{*}{ Estado Civil } & Solteiro & 118 & $86 \%$ \\
\hline & Casado & 16 & $12 \%$ \\
\hline & Separado & 3 & $2 \%$ \\
\hline & Viúvo & 0 & $0 \%$ \\
\hline & Outro & 0 & $0 \%$ \\
\hline & Total & 137 & $100 \%$ \\
\hline \multirow{7}{*}{ Raça } & Branca & 77 & $56 \%$ \\
\hline & Amarela & 3 & $2 \%$ \\
\hline & Negra & 19 & $14 \%$ \\
\hline & Parda & 35 & $26 \%$ \\
\hline & Indígena & 1 & $1 \%$ \\
\hline & Missing & 2 & $1 \%$ \\
\hline & Total & 137 & $100 \%$ \\
\hline \multirow{3}{*}{ Tipo IES } & Pública & 73 & $53 \%$ \\
\hline & Particular & 64 & $47 \%$ \\
\hline & Total & 137 & $100 \%$ \\
\hline
\end{tabular}

Fonte: elaboração dos autores

A média de idade dos participantes é de 25,4, a mediana encontrada foi de 23, com desvio padrão de 7,1 com mínimo de idade de 18 anos e máximo de 58, e 25 dos entrevistados não responderam suas idades (missing). Também a partir dos dados da amostra foram desenvolvidas 6 faixas de distribuição dos respondentes (Tabela 2). Aqui é possível verificar que $42 \%$ dos entrevistados (57) estão na faixa etária de 21 a 25 anos, seguidos de $20 \%$ dos entrevistados com faixa etária de 25 a 30 anos, sendo que somente 4 entrevistados têm idade acima de 50 anos. 
Tabela 2

Distribuição de participantes por intervalos de idade

\begin{tabular}{lcc}
\hline \multirow{2}{*}{ Faixa } & \multicolumn{2}{c}{ Frequência } \\
\cline { 2 - 3 } & Absoluta & Relativa \\
\hline Até 20 anos & 19 & $14 \%$ \\
\hline 21 a 25 & 57 & $42 \%$ \\
\hline 25 a 30 & 27 & $20 \%$ \\
\hline 30 a 40 & 8 & $6 \%$ \\
\hline 40 a 50 & 1 & $1 \%$ \\
\hline Acima de 50 & 4 & $3 \%$ \\
\hline Missing & 21 & $15 \%$ \\
\hline Total & 137 & $100 \%$ \\
\hline Fonte: elaboração dos autores & &
\end{tabular}

A Tabela 3 mostra as medidas de resumo e variabilidade referentes às três principais variáveis do estudo: Maquiavelismo - MQ, Comportamento Contraproducente Organizacional - CCT-O e Comportamento Contraproducente Interpessoal. As estatísticas descritivas, evidenciadas na Tabela 3, permitem inferir que possivelmente a variável MQ possa ser normalmente distribuída, pois todas as medidas de resumo (media, moda e mediana) apresentam valores próximos. Em contrapartida, a distinção entre as mesmas medidas provenientes das variáveis CCT-O e CCT-I permitem inferir uma possível assimetria na distribuição delas.

Tabela 3

Estatística Maquiavelismo, CCT-O e CCT-I

\begin{tabular}{lccc}
\hline & MQ & CCT-O & CCT-I \\
\hline Média & 30,37 & 21,26 & 10,45 \\
\hline Mediana & 30,00 & 20,00 & 9,00 \\
\hline Moda & 30,00 & 12,00 & 7,00 \\
\hline Desvio Padrão & 5,33 & 7,36 & 4,31 \\
\hline Mínimo & 16,00 & 12,00 & 7,00 \\
\hline Máximo & 45,00 & 49,00 & 32,00 \\
\hline
\end{tabular}

Fonte: elaboração dos autores

Com vistas a verificar a adequabilidade dos testes que viabilizam a análise dos dados do estudo, fez-se o teste de Normalidade das variáveis Maquiavelismo - MQ, Comportamento Contraproducente Organizacional - CCT-O e Comportamento Contraproducente Interpessoal - CCT-I. A Tabela 4, a seguir, refere-se ao teste de Normalidade das três principais variáveis do estudo. A observação da tabela permite verificar que ao nível de 0,05 de significância somente a variável Maquiavelismo (MO) apresenta distribuição normal.

Tabela 4

Teste de Normalidade Kolmogorov- Smirnov

\begin{tabular}{lc}
\hline \multicolumn{1}{c}{ Variáveis } & P-Valor \\
\hline Maquiavelismo - MQ & 0,545 \\
\hline Comportamento Contra Producente Organizacional - CCT-O & 0,000 \\
\hline Comportamento Contra Producente Interpessoal - CCT-I & 0,000 \\
\hline Fonte: elaborada pelos autores &
\end{tabular}


Em relação à prevalência do perfil de Maquiavelismo, CCT-O e CCT-I, a Figura 2 evidencia que a maioria dos entrevistados apresentam um perfil moderado de maquiavelismo (65\% dos respondentes). Este resultado vai ao encontro do trabalho de Wakefiel (2008), que considerou que contadores são menos maquiavelistas que outros grupos profissionais estudados e também do trabalho de D'Souza e Lima (2018) e D’Souza, Lima, Jones e Carré (2019), por outro lado, contra ao trabalho de Lopes et al. (2016), que indicou um baixo perfil para estudantes de contabilidade. Quando analisamos os perfis de comportamento contraproducente, encontramos maior concentração de indivíduos no perfil baixo $(73 \%$ e $89 \%$, respectivamente).

A informação acima apresenta uma contribuição importante desta amostra, pois pode-se inferir que, mesmo com preponderância de indivíduos com perfil moderado de comportamento maquiavelista, estes não apresentam indícios de comportamentos contraproducentes nas organizações onde atuam. Essa constatação contradiz alguns estudos recentes na área que relacionaram o perfil de maquiavelismo à atuação desonesta, como a capacidade de enganar e fraudar relatórios financeiros (Murphy, 2012), realizar gerenciamento de resultados (Shafer \& Simmons, 2011) e criar folga orçamentária em decisões sob pressão (Hartmann \& Maas, 2010). Apesar de o questionário aqui aplicado não levar em consideração diretamente tais tipos de comportamentos, os indivíduos não se autodeclaram capazes de manifestar comportamentos contraproducentes em suas tarefas organizacionais.

Maquiavelismo

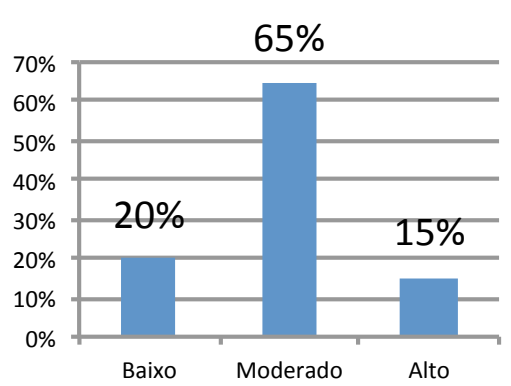

CCT-O

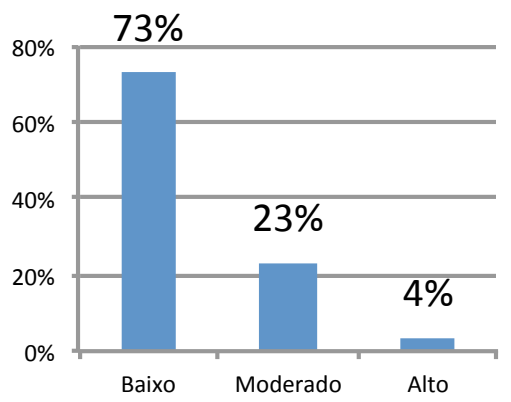

CCT-I

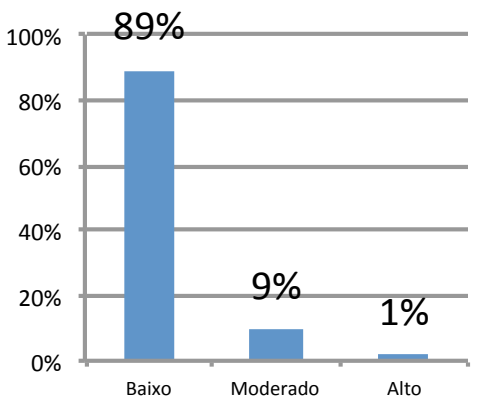

Figura 2. Gráficos de Barras das variáveis MQ, CCT-O e CCT-I

Fonte: elaborado pelos autores

A Tabela 5, dada a seguir, mostra teste de Correlação para as variáveis MQ, Comportamento Contraproducente Organizacional - CCT-O e Comportamento Contraproducente Interpessoal - CCT-I. Pela observação da Tabela 5 , constata-se que existe relação positiva forte $(0,626)$ e significativa ( $\mathrm{p}$-valor=0,000) entre as variáveis Comportamento Contraproducente Organizacional (CCT-O) e Comportamento Contra Producente Interpessoal (CCT-I), o que permite inferir que um maior grau de CCT-O esteja relacionado a um maior CCT-I.

Analisando estatisticamente, a partir da correlação apresentada (Tabela 5), o fato de um indivíduo apresentar perfil maquiavélico não necessariamente representa perfil para comportamento contraproducente nas organizações. De outro lado, a amostra apresenta forte correlação entre Comportamento Contraproducente Organizacional e Comportamento Contraproducente Interpessoal, o que corrobora os resultados de Nascimento, Araújo, Andrade \& Mendonça (2015) que encontraram ao aplicar somente o WDS uma correlação moderada entre CCT-O e CCT-I de 0,46, sendo o resultado deste estudo 0,626. 
Tabela 5

Teste de correlação de Spearman

\begin{tabular}{lcc}
\multicolumn{1}{c}{ Variáveis } & P-Valor & Coeficiente \\
\hline MQ versus CCT-O & 0,073 & $\mathbf{0 , 1 5 4}$ \\
\hline MQ versus CCT-I & 0,056 & $\mathbf{0 , 1 6 4}$ \\
\hline CCT-I versus CCT-O & 0,000 & $\mathbf{0 , 6 2 6}$ \\
\hline
\end{tabular}

Fonte: elaborada pelos autores

A Tabela 6 apresenta os valores médios das variáveis Maquiavelismo - MQ, Comportamento Contraproducente Organizacional - CCT-O e Comportamento Contraproducente Interpessoal CCT-I mensurados em relação a fatores sociais (gênero, estado civil e tipo de ensino). A observação da tabela permite inferir que o traço de maquiavelismo parece ser mais evidente nos homens do que entre as mulheres ( $\mathrm{p}$ -valor=0,0254) e nos estudantes da IES pública ( $p$-valor=0,0823). Em relação ao estado civil, as características maquiavélicas parecem estar mais presentes nos indivíduos casados, apesar dessa associação não ser confirmada estatisticamente.

Apesar de os trabalhos que também apresentaram este tipo de análise não tenham utilizado o mesmo instrumento para levantamento do perfil maquiavelista que os que embasaram este estudo, as autoras Grohmann e Battistella (2012), por exemplo, utilizaram o Machiavellianism Personality Scale e também concluíram que os homens apresentam médias maiores (sem diferenças significativamente estatísticas). Além dessas autoras, Webster e Harmos (2002), Bolino e Tunley (2003), Sweeney, Arnold e Pierce (2009) também identificaram esse comportamento. Tal característica pode ser atribuída aos padrões socialmente desejados dos homens, em que tais posturas exigidas acabam sendo similares aos padrões definidos pelo perfil maquiavelista.

Tabela 6

Valores Médios das Variáveis MQ, CCT-O, CCT-I

\begin{tabular}{lccccccc}
\hline \multirow{2}{*}{ Variável } & \multicolumn{2}{c}{ Gênero } & \multicolumn{3}{c}{ Estado Civil } & \multicolumn{2}{c}{ Tipo de Ensino } \\
\cline { 2 - 9 } & Masculino & Feminino & Casado & Solteiro & Divorciado & Privado & Público \\
\hline MQ & 31,32 & 29,51 & 31,16 & 30,27 & 30,33 & 20,28 & 31,32 \\
\hline CCT-O & 20,84 & 21,7 & 20,87 & 21,33 & 19,33 & 19,25 & 23,01 \\
\hline CCT-I & 10,58 & 10,30 & 10,00 & 10,54 & 9,33 & 8,92 & 11,79 \\
\hline
\end{tabular}

Fonte: elaborado pelos autores

De modo a verificar se as associações apresentadas na Tabela 6 eram estatisticamente significativas, foram produzidas as Tabelas 7, 8 e 9, evidenciadas abaixo, que se referem ao teste de associação para as variáveis Maquiavelismo - MQ, Comportamento Contraproducente Organizacional - CCT-O e Comportamento Contraproducente Interpessoal - CCT-I segregadas por fatores sociais (gênero, estado civil e tipo de instituição de ensino - publica ou privada).

A Tabela 7, referente ao teste de média, para as variáveis $\mathrm{MQ}$, Comportamento Contraproducente Organizacional - CCT-O e Comportamento Contraproducente Interpessoal - CCT-I, refere-se à comparação dos valores médios de cada uma das variáveis em relação ao gênero (masculino e feminino). A observação da tabela permite perceber que ao nível de 0,05 todas as variáveis analisadas apresentam associações significativas. Cabe destacar que em relação co CCT-O, as mulheres relataram possuir um grau maior, o que poderia ser um indício de mudança de comportamento quanto ao papel historicamente relatado e esperado para as mulheres (War \& Beck, 1990). 
Tabela 7

Teste de Associação - por gênero

\begin{tabular}{lc}
\hline \multicolumn{1}{c}{ Variáveis } & P-Valor \\
\hline Maquiavelismo - MQ & 0,00145 \\
\hline Comportamento Contra Producente Organizacional - CCT-O & 0,0040 \\
\hline Comportamento Contra Producente Interpessoal - CCT-I & 0,0001 \\
\hline Fonte: elaborada pelos autores &
\end{tabular}

A Tabela 8 evidencia o teste de Média para as variáveis MQ, Comportamento Contraproducente Organizacional - CCT-O e Comportamento Contraproducente Interpessoal - CCT-I em relação ao estado civil dos amostrados. A análise da tabela permite observar que somente a variável Maquiavelismo (MQ) não apresenta diferenças significativa em relação aos seus valores médios para os diferentes tipos de estado civil (solteiro, casado e divorciado). Para as demais variáveis CCT-I e CCT-O, percebe-se a existência de diferenças significativas entre os estados civis.

Tabela 8

Teste de Associação -por estado civil

\begin{tabular}{ll}
\hline \multicolumn{1}{c}{ Variáveis } & P-Valor \\
\hline Maquiavelismo - MQ & 0,8271 \\
\hline Comportamento Contra Producente Organizacional - CCT-O & 0,0465 \\
\hline Comportamento Contra Producente Interpessoal - CCT-I & 0,0026 \\
\hline Fonte: elaborada pelos autores &
\end{tabular}

Em relação ao tipo de instituição de ensino superior - pública e privada - o teste de Associação empregado indicou ao nível de significância de 10\% para MQ e de 1\% para as demais dimensões que há associação com o tipo de IES. Dessa forma, pela Tabela 4, o que se verifica é que nas três dimensões os estudantes da IES pública tiveram média maior que os da IES privada.

Tabela 9

Teste de Associação -por tipo de ensino

\begin{tabular}{ll}
\hline \multicolumn{1}{c}{ Variáveis } & P-Valor \\
\hline Maquiavelismo - MQ & 0,0823 \\
\hline Comportamento Contra Producente Organizacional - CCT-O & 0,0029 \\
\hline Comportamento Contra Producente Interpessoal - CCT-I & 0,0002 \\
\hline Fonte: elaborada pelos autores &
\end{tabular}

Também foi realizado um teste de Correlação entre as dimensões MQ, CCT-O e CCT-I e a idade dos respondentes.

Tabela 10

Correlação MQ, CCT-O, CCT-I com Idade

\begin{tabular}{|c|c|c|c|c|}
\hline \multicolumn{2}{|c|}{ Categoria } & \multirow{2}{*}{$\frac{\text { MQ }}{0.0368}$} & \multirow{2}{*}{$\begin{array}{l}\text { СCT-O } \\
0.1141\end{array}$} & \multirow{2}{*}{$\frac{\text { CCT-I }}{0.0082}$} \\
\hline \multirow{2}{*}{ Idade } & Correlação & & & \\
\hline & p-valor & 0.6961 & 0.2167 & 0.9296 \\
\hline
\end{tabular}

Fonte: elaborada pelos autores 
De acordo com a Tabela 10, as correlações além de baixas (todas abaixo de 0,15 ) também não são significativas ( $\mathrm{p}$-valor $>0,1$ ), o que é indício de que a idade não influencia aquelas três variáveis. Tal resultado pode estar relacionado à amostra, já que aproximadamente $76 \%$ dela tem idade inferior a 30 anos, portanto, composta majoritariamente de jovens, o que pode ter influenciado a identificação do efeito da experiência de vida nas variáveis MQ, CCT-O e CCT-I, apesar de já ter sido mencionado que o efeito da idade parece ser controverso nas variáveis estudadas (Cullen \& Sackett, 2003, Sweeney, Arnold \& Pierce, 2009, D’Souza, 2016, Thiel et al., 2012).

Em resumo, a partir dos dados é possível aludir que existe associação positiva e baixa, mas estatisticamente não significativa entre o Maquiavelismo e o Comportamento Contraproducente, tanto o Organizacional quanto o Interpessoal ( $\mathrm{p}$-valor $>0,05$ ). Essa análise permite dizer que há evidências para se rejeitar a $\mathrm{H}_{1}$ o que é contrário a diversos trabalhos, como Shafer e Simmons (2008), Hartmann e Maas (2010), Zettler, Friedrich e Hilbig (2011), Murphy (2012), O'Boyle et al., 2012). Todavia, para os autores, isso pode ser esclarecido em razão do perfil majoritariamente moderado dos estudantes que participaram da pesquisa (65\% deles tem esse perfil). Conforme Harrell \& Hartnagel (1976), Dahling, Whitaker \& Levy (2009), Hartmann e Maas (2010) e Zettler, Friedrich \& Hilbig, (2011), a associação entre maquiavelismo e comportamento contraproducente seria percebida apenas em perfis de alto nível de maquiavelismo, considerando que suas limitações morais seriam mais elásticas do que os indivíduos com perfis mais baixos e moderados (Murphy, 2012).

Outra hipótese que os dados sustentam são às relacionadas ao gênero dos respondentes. $\mathrm{As}_{2} \mathrm{e}_{3}$ sinalizaram que o sexo dos respondentes é algo que influencia as variáveis e, neste estudo, foi constatado que elas não poderiam ser rejeitas, ou seja, há evidências que indicam que o gênero dos respondentes é algo que está associado aos graus de Maquiavelismo e Comportamento Contraproducente, conforme Ward e Beck (1990), Webster e Harmos (2002), Bolino e Tunley (2003), Sweeney, Arnold e Pierce (2009), Grohmann e Battistella (2012), Avelino e Lima (2017), D'Souza e Lima (2018), D'Souza, Lima, Jones, Daniel e Carré (2019).

Em relação às $\mathrm{H}_{4}$ e $\mathrm{H}_{5}$, novamente com base no que foi levantado, constata-se que a $\mathrm{H}_{4}$ não apresentou associação estatisticamente significativa ( $\mathrm{p}$-valor $=0,8271$ ); por outro lado, a $\mathrm{H}_{5}$ se mostrou estatisticamente significativa ( $\mathrm{p}$-valor $<0,05$ ). Assim, considerando que foi identificada associação em relação ao estado civil dos respondentes, os dados desta pesquisa apontam que respondentes casados não têm nível de Maquiavelismo maior do que os demais estados civis, mas solteiros que participaram do estudo relataram possuir maior Comportamento Contraproducente.

Para as $\mathrm{H}_{6}$ e $\mathrm{H}_{7}$, foi encontrado indícios que permitem concluir que para a primeira não há associação estatisticamente significativa ( $\mathrm{p}$-valor $=0,0823$ ), ao passo que para a segunda a associação é estatisticamente significativa ( $\mathrm{p}$-valor $<0,01)$. Essas hipóteses indicavam que os estudantes participantes da pesquisa que tivessem origem em IES públicas apresentariam grau de Maquiavelismo e Comportamento Contraproducente mais marcado do que aqueles de IES privadas, o que se mostrou, portanto, parcialmente aderente a outros trabalhos (Formiga, 2004, Santos, 2012, Bublitz, Guido, Lopes \& Freitas, 2016).

Finalmente, com relação à idade, base para as $\mathrm{H}_{8}$ e $\mathrm{H}_{9}$, os dados da pesquisa demonstraram que a relação é fraca e não significativa. Portanto, tanto a H8 quanto a H9 foram rejeitadas (p-valor $>0,1$ ). 


\section{Conclusão}

Esse trabalho buscou avaliar a relação existente entre os traços de personalidade maquiavélicos e os traços de contraproducência nos futuros profissionais da contabilidade. Para isso foram aplicados 137 questionários em quatro instituições de Ensino Superior: a Universidade Federal de Minas Gerais (UFMG), a Universidade Federal do Espírito Santo (UfesFES), a Universidade de Formiga (UniforNIFOR-MG) e a Faculdade Pitágoras (Unidade Divinópolis), sendo a amostra desse estudo constituída de duas instituições públicas e de duas privadas.

A literatura expõe que os traços de personalidade podem explicar o comportamento das pessoas, além de justificar suas atitudes negativas e positivas. A demonstração desses traços, por vezes, pode demonstrar desvantagens organizacionais, mas podem também comprovar vantagens, especialmente, quando o grau encontrado está em níveis moderados (D’Souza \& Lima, 2015). Além disso, diversas pesquisas apresentam uma visão negativa do perfil maquiavelista, o que se deve, especialmente, ao seu comportamento dentro da organização, que é caracterizado pela manipulação de algo em seu benefício.

Ao conceituar o maquiavelismo, a literatura associa suas principais características a personalidades que agem em benefício próprio, com frieza, uma vez que grande parte dos autores que abordam sobre o tema descrevem o indivíduo maquiavelista como alguém que considera seus interesses individuais acima dos interesses do grupo em que está inserido. O comportamento contraproducente dos colaboradores de uma dada instituição pode desvirtuar a empresa do objetivo proposto por seus principais executivos e acionistas, e indivíduos com características maquiavélicas podem conduzir a empresa por caminhos não satisfatórios às suas políticas e práticas.

A partir do pressuposto de que a Contabilidade abrange informações patrimoniais da organização, surge a necessidade de verificar se contadores maquiavelistas poderiam manifestar, por meio de seu ofício, comportamentos contraproducentes, elaborando informações distorcidas e que não retratassem a real posição patrimonial da entidade.

O principal achado deste trabalho foi a inexistência de evidências empíricas que permitam concluir sobre a existência de relacionamento entre os comportamentos maquiavelistas e os contraproducentes, em relação aos futuros profissionais da contabilidade. Apesar de se poder afirmar que o traço moderado de maquiavelismo está presente na maioria dos entrevistados (65\%), os resultados de contraproducência nos mostraram que a maioria dos entrevistados se autodeclaram com perfil baixo de contraproducência organizacional e interpessoal (73\% e $89 \%)$. Este resultado vai contra a resultados encontrados por diversos autores que concluem que indivíduos com moderados a altos perfis de maquiavelismo decidem de forma oportunista, por meio de estratégias que mantenham sua reputação e oportunizem o alcance dos objetivos e metas pessoais (Milan, 2014, Zettler \& Hilbig, 2010, VandenBos, 2010, D’Souza, 2016), Shafer \& Simmons, 2008). Todavia, conforme destacam Judge et al. (2009), Zettler et al. (2011), Jones e Paulhus (2010) e D’Souza (2016), quando os indivíduos apresentam traços moderados em relação às características da Dark Triad, eles podem revelar talentos, criatividade, inovação e melhores desempenhos individuais e empresariais, portanto, algum grau de maquiavelismo pode ser benefício.

Os resultados permitem inferir que o traço de maquiavelismo parece ser em média mais evidente nos homens do que entre as mulheres ( $31 \%$ homem, e $29 \%$ mulheres) como o encontrado pelas autoras Grohmann e Battistella (2012), ao utilizarem um instrumento diferente, conhecido como Machiavellianism Personality Scale.

A identificação de perfis profissionais auxiliam as empresas em seus processos seletivos como também em avaliações periódicas com intuito de promover o desenvolvimento organizacional (Ferreira, 2013). Assim, os resultados aqui apresentados podem auxiliar profissionais da área de recursos humanos a melhor recrutar e treinar colaboradores. Autores, como Judge et al., 2009 e Jones \& Paulhus, 2011, identificaram que pessoas com perfil maquiavélico são estrategistas e calculistas e possuem destreza para atuarem em negócios complexos. Zettler e Solga (2013) concluem que pessoas com alto grau de maquiavelismo possuem melhor comportamento de cidadania organizacional. Como contribuição deste estudo, entender que o perfil maquiavelista moderado não apresenta necessariamente comportamento contraproducente pode auxiliar a área gerencial em seus processos seletivos e avaliações, revelando subsídios que rechaçam paradigmas não raro resistentes a esse perfil profissional e que o associam, muitas vezes injustamente, a modelos de comportamento não desejáveis. 
Inclusive, os dados dessa pesquisa evidenciam uma relação positiva entre o comportamento contraproducente interpessoal e organizacional, permitindo inferir que o maior nível de contraproducência organizacional entre os profissionais associa-se a maiores níveis de contraproducência interorganizacional. Esse achado pode ser confirmado nos estudos de Nascimento et al. (2015), que encontraram uma correlação moderada sugerindo que são relacionadas.

Os resultados encontrados apontam para a necessidade de mais estudos no contexto brasileiro que analisem o perfil do profissional da contabilidade, com vistas a evidenciar manifestações de comportamentos de maneira mais clara, recomendando-se inclusive, a inclusão de uma variável que sinalize o tempo de experiência profissional do respondente, pois, desse modo, poderia ser possível analisar se o maquiavelismo ou o comportamento contraproducente pode ser influenciados por aquela variável.

\section{Referências}

Almeida, O. P., Laranjeira, R. \& Dractu, L. (1996). Manual de psiquiatria. Guanabara Koogan.

Alves, M. A. (2008). A Ética como Virtude Cívica em Maquiavel. Thaumazein: Revista Online de Filosofia, 2(3).

Avelino, B. C. \& Lima, G. A. S. F. (2017). Narcisismo e desonestidade acadêmica. Revista Universo Contábil, 13(3), pp. 70-89. doi: 10.4270/ruc.2017319

Bennett, R. J. \& Robinson, S. L. (2000). Development of a measure of workplace deviance. Journal of applied psychology, 85(3), pp. 349-360. doi: 10.I037//0021-9010.85.3.349

Bolino, M. C. \& Turnley, W. H. (2003). More than one way to make an impression: Exploring profiles of impression management. Journal of Management, 29(2), pp. 141-160. doi: https://doi. org/10.1177/014920630302900202

Bublitz, S., de Azevedo Guido, L., Lopes, L. F. D., \& de Oliveira Freitas, E. (2016). Associação entre estresse e características sociodemográficas e acadêmicas de estudantes de enfermagem. Texto \& Contexto Enfermagem, 25(4), pp. 1-7. doi: dx.doi.org/10.1590/0104-07072016002440015

Cyriac, K., \& Dharmaraj, R. (1994). Machiavellianism in Indian management. Journal of Business Ethics, 13(4), pp. 281-286. doi: https://doi.org/10.1007/BF00871674

Cullen, M. J. \& Sackett, P. R. (2003). Personality and Counterproductive Workplace Behavior. In Barrick, M. R., \& Ryan, A. M. Personality and Work: Reconsidering the Role of Personality in Organizations. Jossey-bass.

D’Godoy, S. L. \& Noronha, A. P. P. (2005). Instrumentos psicológicos utilizados em seleção profissional. Revista do Departamento de Psicologia-UFF, 17(1), pp.139-159. doi: http://dx.doi.org/10.1590/ S0104-80232005000100011

D'Souza, M. F. \& Lima, G. A. S. F. (2015). The Dark Side of Power: The Dark Triad in Opportunistic Decision-Making. Advances in Scientific and Applied Accounting, 8(2), pp. 135-156. doi: http://dx.doi. org/10.14392/asaa.2015080201

D’Souza, M. F. (2016). Manobras financeiras e o Dark Triad: o despertar do lado sombrio na gestão . Doctoral dissertation, Universidade de São Paulo, São Paulo, SP, Brasil.

D’Souza, M. F. \& Jones, D. N. (2017) Taxonomia da Rede Científica do Dark Triad: Revelações no Meio Empresarial e Contábil. REPeC - Revista de Educação e Pesquisa em Contabilidade, 11(3), pp. 296313. doi: http://dx.doi.org/10.17524/repec.v11i3.1588

D’Souza, M. F., \& de Lima, G. A. S. F. (2018). Escolha de carreira: o Dark Triad revela interesses de estudantes de Contabilidade. Revista de Contabilidade e Organizações, 12, e151837. doi: https://doi. org/10.11606/issn.1982-6486.rco.2018.151837 
D’Souza, M. F., Lima, G. A. S. F., Jones, D. N. \& Carré, J. R. (2019). Eu ganho, a empresa ganha ou ganhamos juntos? Traços moderados do Dark Triad e a maximização de lucros. Revista Contabilidade \& Finanças, 30(79), pp. 123-138. doi: https://dx.doi.org/10.1590/1808-057x201806020

Dahling, J. J., Whitaker, B. G., \& Levy, P. E. (2009). The development and validation of a new Machiavellianism scale. Journal of management, 35(2), 219-257. doi: https://doi.org/10.1177/0149206308318618

Dalal, R. S. (2005). A meta-analysis of the relationship between organizational citizenship behavior and counterproductive work behavior. Journal of applied psychology, 90(6), 1241. doi: 10.1037/00219010.90.6.1241

Dalbosco, S. N. P. \& da Silva Consul, J. (2011). A importância da Avaliação psicológica nas organizações. Revista de Psicologia da IMED, 3(2), pp. 554-558.

Devore, J. L. (2006). Probabilidade e estatística: para engenharia e ciências. São Paulo: Pioneira Thomson Learning.

Formiga, N. (2004). Atribuição de causalidade e rendimento acadêmico: predição e diferença em alunos da universidade pública e privada. Revista de Psicologia da UNC, 2(1), pp. 3-14.

Ferreira, M. F (2013). Relação entre traços de personalidade, percepção de justiça distributiva, satisfação e comportamentos contraproducentes no trabalho. Disseratção de Mestrado, Universidade Federal de Minal Gerais, Belo Horizonte, Minas Gerais. Recuperado em 24 abr., 2017 de http://www.bibliotecadigital.ufmg.br/dspace/handle/1843/BUBD-A3KF6D

Fine S., Horowitz, I., Weigler, H. \& Basis, L. (2010). Is good character good enough? The effects of situational variables on the relationship between integrity and counterproductive work behaviors. $\mathrm{Hu}$ man Resource Management Review, 20, pp. 73-84. doi: http://doi.org/10.1016/j.hrmr.2009.03.010

Furnham, A., Richards, S. C. \& Paulhus, D. L. (2014). The dark triad of personality: a 10 year review. Social and Personality Psychology Compass, 7(3), pp. 199-216. doi: doi.org/10.1111/spc3.12018

Furnham, A., Richards, S., Rangel, L., \& Jones, D. N. (2014). Measuring malevolence: Quantitative issues surrounding the Dark Triad of personality. Personality and individual differences, 67, pp. 114-121. doi: https://doi.org/10.1016/j.paid.2014.02.001

Godoy, S. L., \& Noronha, A. P. P. (2005). Instrumentos psicológicos utilizados em seleção profissional. Revista do Departamento de Psicologia-UFF, 17(1), pp. 139-159.

Gomes, J. C. L. (1990). Maquiavel e a moderna concepção do político. Dissertação de Mestrado, Universidade Federal de Minas Gerais, Belo Horizonte, MG, Brasil.

Grohmann, M. Z. \& Flores Battistella, L. (2012). Maquiavelismo nas Organizações: o relacionamento entre perfil individual e personalidade maquiavélica. Invenio, 15(28), pp. 101-118.

Harrell, W. A., \& Hartnagel, T. (1976). The impact of Machiavellianism and the trustfulness of the victim on laboratory theft. Sociometry. 39(2), pp. 157-165 doi: http://dx.doi.org/10.2307/2786216

Hartmann, F. G. H. \& Maas, V. S. (2010). Why business unit controllers create budget slack: involvement in management, social pressure, and machiavellianism. Behavioral Research in Accounting, 22(2), pp. 27-49. doi: doi.org/10.2308/bria.2010.22.2.27

Jain, K. \& Bearden, J. N. (2011). Machiavellianism and Overconfidence (March 2, 2011). INSEAD Working Paper No. 2011/29/DS. doi: http://dx.doi.org/10.2139/ssrn.1774523

Jensen, J. M. \& Patel. P. C., (2011) Predicting counterproductive work behavior from the interaction of personality traits. Personality and Individual Differences. 5, pp. 466-471. doi: doi.org/10.1016/j. paid.2011.04.016

Jones, D. N. \& Paulhus, D. L. (2010). Mating strategies among the dark triad: relationship focus, retention, and infidelity (under review). [Working paper]. 
Jones, D. N. \& Paulhus, D. L. (2011). Differentiating the dark triad within the interpersonal circumplex. In L. M., Horowitz, \& S., Strack. Handbook of interpersonal psychology (pp. 249-269). New York: Wiley and Sons.

Judge, T. A., Piccolo, R. F. \& Kosalka, T. (2009). The bright and dark side of leader traits: a review and theoretical extension of the leader trait paradigm. The Leadership Quarterly, 20(6), pp. 855-875. doi: doi. org/10.1016/j.leaqua.2009.09.004

Kish-Gephart, J. J., Harrison, D. A., \& Treviño, L. K. (2010). Bad apples, bad cases, and bad barrels: meta-analytic evidence about sources of unethical decisions at work. Journal of applied psychology, 95(1), pp. 1-31. doi: 10.1037/a0017103

Lima, L. S., Garcia, F. C. \& Pereira, L. Z. (2012). Valores Relativos ao Trabalho e Maquiavelismo: Estudo de Caso Envolvendo Gestores de uma Rede Varejista com Atuação no Estado de Minas Gerais. Revista Gestão Organizacional, 5(2), pp. 149-160.

Lopes, S. S., Cardoso, P. R., Reina, D. \& Reina, D. R. M. (2016, November). Dark Triad: Análise Do Perfil De Personalidade Em Estudades Da Área Contábil. Congresso UnB de Contabilidade e Governança, Brasília, DF, Brasil, 2.

Malinowski, C. (2009). The relationship between Machiavellianism and undergraduate student attitudes about hypothetical marketing moral dilemmas. Competitiveness Review: An International Business Journal, 19(5), pp. 398-408. doi: https://doi.org/10.1108/10595420910996019

Marconi, M. D. A., \& Lakatos, E. M. (2002). Técnicas de pesquisa.V. 2. São Paulo: Atlas.

Marcus B. \& Schuler H. (2004). Antecedents of counterproductive behavior at work: A general perspective. Journal of Applied Psychology, 89, pp. 647-660. doi: 10.1037/0021-9010.89.4.647

Milan, J. C. (2014). Comportamento oportunista nas escolhas contábeis: a influência das emoções e do traço de personalidade. Dissertação de Mestrado. Fundação de Comércio Alvares Penteado (FECAP), São Paulo, SP, Brasil..

Murphy, P. R. (2012). Attitude, machiavellianism and the rationalization of misreporting. Accounting, Organizations and Society, 37(4), pp. 242-259. doi: https://doi.org/10.1016/j.aos.2012.04.002

Mynatt, P., J. Omundson, R. G. Schroeder \& M. Stevens (1997). The impact of Anglo-Hispanic ethnicity, gender, position, personality and job satisfaction on turnover intentions: A path analytic investigation. Critical Perspectives in Accounting, 8, pp. 657-883. doi: https://doi.org/10.1006/cpac.1997.0161

Nascimento, E., Araújo, A. C., de Andrade, J. E.; Mendonça, M. \& Maria, L. (2015). Adaptação transcultural da Workplace Deviance Scale (WDS) para o contexto brasileiro. Revista Psicologia. Organizações e Trabalho, 15(4). doi: http://dx.doi.org/10.17652/rpot/2015.4.649

Noronha, A. P. P. (2002). Análise de testes de personalidade: qualidade do material, das instruções, da documentação e dos itens qualidade de testes de personalidade. Estudos de Psicologia (Campinas), 19(3), pp. 55-65.

O’Boyle, E. H., Jr., Forsyth, D. R., Banks, G. C. \& McDaniel, M. A. (2012). A meta-analysis of the dark triad and work behavior: a social exchange perspective. Journal of Applied Psychology, 97(3), pp. 557-579. doi: 10.1037/a0025679

Paulhus, D. L., \& Williams, K. M. (2002). The dark triad of personality: Narcissism, Machiavellianism, and psychopathy. Journal of research in personality, 36(6), pp. 556-563. doi: https://doi.org/10.1016/ S0092-6566(02)00505-6

Robinson, S. \& Bennett, R. (1995). A typology of deviant workplace behaviors: A multi-dimensional scaling study. Academy of Management Journal, 38, pp. 555-572. doi: https://doi.org/10.5465/256693 
Rocha, J. D., Pinto, F. R. \& da Silva, J. S. (2015). Maquiavelismo em lojistas: um retorno a origem. Revista de Administração da UFSM, 8(2), pp. 202-215. doi: http://dx.doi.org/10.5902/198346595964

Roodpooshti, F. R., Nikoomaram, H. \& Mahfoozi, G. (2012). Machiavellianism and accountants ethical approach: Evidence from Iran. Journal of Basic and Applied Scientific Research, 2(10), pp. 10576-10581.

Rotundo, M., \& Sackett, P. R. (2002). The relative importance of task, citizenship, and counterproductive performance to global ratings of job performance: A policy-capturing approach. Journal of applied psychology, 87(1), pp. 66-80. doi: 10.1037//0021-9010.87.1.66

Santos, N. D. A. (2012). Determinantes do desempenho acadêmico dos alunos dos cursos de ciências contábeis. Dissertação de doutorado na Universidade de São Paulo, São Paulo, SP, Brasil..

Shafer, W. E., \& Simmons, R. S. (2008). Social responsibility, Machiavellianism and tax avoidance: A study of Hong Kong tax professionals. Accounting, Auditing \& Accountability Journal, 21(5), 695-720. https://doi.org/10.1108/09513570810872978

Siegel, S. \& Castellan Jr, N. J. (2006). Estatística não-paramétrica para ciências do comportamento. Artmed Editora.

Sweeney, B., Arnold, D. \& Pierce, B. (2009). The impact of perceived ethical culture of the firm and demographic variables on auditors' ethical evaluation and intention to act decisions. Journal of Business Ethics, 93(4), pp. 531-551. doi: 10.1007/s10551-009-0237-3

Thiel, C. E., Bagdasarov, Z., Harkrider, L., Johnson, J. F. \& Mumford, M. D. (2012). Leader ethical decision-making in organizations: Strategies for sensemaking. Journal of Business Ethics, 107(1), pp. 49-64. doi: 10.1007/s10551-012-1299-1

VandenBos, G. R. (Org.). (2010). Dicionário de psicologia da American Psychological Association. Porto Alegre: Artmed.

Vardi, Y. \& Weitz, E., (2004). Misbehavior in organizations Theory, research, and managemen. Lawrence Erlbaum Associates: Mawah, New Jersey.

Wakefield, R. L. (2008). Accounting and Machiavellianism. Behavioral Research in Accounting, 20, pp. 115129. doi: https://doi.org/10.2308/bria.2008.20.1.115

Ward, D. A., \& Beck, W. L. (1990). Gender and dishonesty. The Journal of Social Psychology, 130(3), pp. 333-339. doi: https://doi.org/10.1080/00224545.1990.9924589

Webster, R. L., \& Harmon, H. A. (2002). Comparing levels of Machiavellianism of today's college students with college students of the 1960s. Teaching Business Ethics, 6(4), pp. 435-445. doi: https:// doi.org/10.1023/A:1021149204098

Weller, J. A. \& Thulin, E. W. (2012). Do honest people take fewer risks? Personality correlates of risk-taking to achieve gains and avoid losses in Hexaco space. Personality and individual differences, 53(7), pp. 923-926. doi: https://doi.org/10.1016/j.paid.2012.06.010

Zettler, I., \& Hilbig, B. E. (2010). Honesty-humility and a person-situation interaction at work. European Journal of Personality, 24(7), pp. 569-582. doi: https://doi.org/10.1002/per.757

Zettler, I. \& Solga, M. (2013). Not enough of a 'dark' trait?: linking machiavellianism to job performance. European Journal of Personality, 27, pp. 545-554. doi: https://doi.org/10.1002/per.1912

Zettler, I., Friedrich, N. \& Hilbig, B. E. (2011). Dissecting work commitment: The role of Machiavellianism. Career Development International, 16(1), pp. 20-35. doi: https://doi.org/10.1108/13620431111107793 